\title{
Rescheduling nursing shifts: scoping the challenge and examining the potential of mathematical model based tools.
}

Forthcoming in Journal of Nursing Management.

Alistair Clark BA MA PhD FORS, Reader in Operational Research, Department of Engineering Design and Mathematics, University of the West of England, Bristol.

Pam Moule RGN BSc MSc EdD, Professor of Health Services Research (Service Evaluation), Director of the Centre for Health and Clinical Research, University of the West of England, Bristol.

Annie Topping RGN BSc PGCE PhD, Professor of Nursing, Director of the Centre for Health \& Social Care Research, University of Huddersfield.

Martin Serpell BSc AKC MSc MBA PhD, Senior Lecturer, Department of Computer Science and Creative Technologies, University of the West of England, Bristol.

Acknowledgements. This project received Start-up funding as part of the EPSRC-funded heat@uwe programme (Grant Reference: EP/H000380/1). The project is entitled 'heat@uwe: Bridging the gaps in Health, Environment and Technology Research' 


\section{$\underline{\text { Abstract }}$}

Aims: To review research in the literature on nursing shift scheduling/rescheduling, and report key issues identified in a consultation exercise with managers in four English NHS trusts to inform the development of mathematical tools for rescheduling decision-making.

Background: Shift rescheduling is unrecognised as an everyday time-consuming management task with different imperatives than scheduling. Poor rescheduling decisions can have quality, cost and morale implications.

Evaluation: A systematic critical literature review identified rescheduling issues and existing mathematic modelling tools. A consultation exercise with nursing managers examined the complex challenges associated with rescheduling.

Key issues: Minimal research exists on rescheduling compared to scheduling. Poor rescheduling can result in greater disruption to planned nursing shifts and may impact negatively on the quality and cost of patient care, and nurse morale and retention. Very little research examines management challenges or mathematical modelling for rescheduling.

Conclusion: Shift rescheduling is a complex and frequent management activity that is more challenging than scheduling. Mathematical modelling may have potential as a tool to support managers to minimise rescheduling disruption.

Implications for Nursing Management: The lack of specific methodological support for rescheduling that takes into account its complexity increases the likelihood of harm for patients and stress for nursing staff and managers.

Keywords: Scheduling, rescheduling, rostering, rerostering, nursing shifts. 


\section{Introduction and Aims}

A daily challenge for nurse managers working in hospital in-patient settings is rostering, or scheduling staff to ensure safe and effective care can be provided. Staff allocation needs to balance service requirements with fairness and cost effectiveness. Effective schedules not only provide the required levels and skill-mix of nursing and support staff to ensure optimum care 24 hours a day, but also ensure personnel are not unduly fatigued, perceive work-life balance is considered and contributes to overall staff morale. Irrespective of the quality of any planning, rescheduling frequently occurs due to staff illness, absenteeism, unforeseen requests to change shifts, or changes to staffing requirements as a consequence of patient care needs. Nurse managers have to respond and this often requires replacement staff to be sought. The urgency can mean that some staff are moved from other duties, reallocated from other wards, or have their planned roster changed at short notice.

Staff fatigue and dissatisfaction are common complaints and both potentially can impact on the quality of care. Excessive alterations to planned rotas can disrupt sleep patterns and invade the personal lives of staff and their families and friends. Increased absenteeism is associated with number of shift changes made at short notice, as is denial of leave or shift pattern requests (Silvestro and Silvestro, 2008). The potential for a spiral of illness and absenteeism to become out of control is normally managed, nevertheless if unchecked can result in extra costs if temporary staff need to be recruited. The management imperative is to minimise scheduling disruption with ideally no, or few, cost consequences. The net organisational impact of shift rescheduling is a daily, onerous time-consuming task for managers, yet one with the potential to cause harmful disruption if not well managed.

The aims of this paper are threefold: to present a review of the available research relating to in-patient hospital nursing and support staff rescheduling; to report the results of a limited but nevertheless illuminating consultation exercise of the real world rescheduling issues faced by nursing managers drawn from four English National Health Service (NHS) Trusts; and to examine the potential of mathematical-modelling tools to support decisionmaking.

The end objective of the exploratory work presented in this paper is to inform the development, validation and implementation of a mathematical-model based scheduling tool to support managers involved in the rescheduling of nurse shifts for use on a shift-by-shift basis in order to maximise patient care delivery within an unstable resource base.

In the context of this paper, the terms 'rostering' and 'scheduling' are used interchangeably as having identical meanings. The same also applies to the terms 'rerostering' and 'rescheduling'.

\section{Background}

Rostering staff in any organisation is a balancing act between the requirements of the service, and available staff resource. Shift work has the potential to impact negatively on the quality of life of staff, and ultimately on the productivity and quality of services provided. Organisations have different staffing needs and contexts that exert their individual limitations so that distinct local scheduling approaches develop as a consequence (Ernst et al., 2004). For example, in the airline industry aircrew scheduling synchronises flight schedules, aircraft availability, and staff health and safety requirements, whereas call centre activity may be more predictable with identifiable peaks and troughs of activity which can be planned. Most hospital wards have to be staffed 24 hours a day, 7 days a week, with a specified minimum 
number of staff often further complicated by specific requirements in terms of skill or grade mix and competencies.

Poor scheduling decisions carry risks, including adverse effects on the quality of care. Poorly constructed shift schedules can lead to fatigue, which can in turn lead to mistakes and poorer standards of patient care. Roger et al (2004) found that significant increases in mistakes have been associated with work patterns where nurses undertake shifts of more than 12 hours, work more than 40 hours in a one week period, stay longer than their scheduled shift, or work scheduled overtime. The number of days a particular shift is worked before changing to another, the length of break between changing shift patterns, and the distribution of days off can impact on an individual's health and productivity at work (Kostreva et al. 2002). Over a decade ago the Royal College of Nursing ( $\mathrm{RCN})$ reported that nurses working a rotating pattern of day and night shifts were more likely to want to leave the NHS or seek employment in posts with regular working hours.

\section{Patient care}

Poor patient care has been linked with inappropriate skill mix (McGillis Hall et al., 2004; Goldstein et al., 2000), too few nurses (Taylor et al., 1999; Aiken et al., 2002) and with shifts 12 or more hours long (Rogers et al., 2004). Rafferty et al. (2007) and Aiken et al. (2012) have demonstrated that these findings are transferable across health systems and not unique to a particular country or organisation. However, a detailed review of 15 studies by Butler et al (2011) found only very limited evidence that replacing registered nurses with unqualified nursing assistants impacted on patient outcomes. This contrasts with earlier findings by Needleman (2002) who concluded that a higher proportion of care hours from registered nurses was associated with a better quality of patient care. Systematic reviews have demonstrated a significant association between nurse staffing levels and the adjusted odds ratios for hospital-related mortality, failure to rescue, and other patient outcomes (Kane et al., 2007; Needleman, 2002).

\section{Nurse morale}

A link between nurse scheduling policies and nurse morale has also been established (Hegney et al, 2006). Too few nurses on a ward (Taylor et al., 1999 and Aiken et al., 2002), working long hours (Rogers et al., 2004) and/or working inequitable shifts (Wilson, 2002; Dunn et al., 2005) all contribute to reduced nurse morale. Dunn et al. (2005) found that nurse scheduling ranked third highest out of ten factors that could improve nurse morale, after quality of patient care and relationships with other nursing staff. Offering some choice about the shifts individual nurses work can improve the perception of fairness associated with shift allocation, which in turn impacts on morale and has an overall positive effect on staff well being(Pryce et al., 2006).

\section{Cost of care}

The over-staffing of wards (Newbold, 2008) and the use of bank or agency staff (Silvestro and Silvestro, 2008) directly increases costs. Increased indirect costs are incurred by longer patient stays as a consequence of poor patient care (Kane et al., 2007; Thungjaroenkul et al., 2007), high levels of staff turnover (Jones, 2005 and 2008; Hayes and Bonner, 2010) and staff absenteeism (Silvestro and Silvestro, 2008). Hospital costs are reduced when better patient care is delivered. Hence, there is a direct relationship between costs, length of patient 
stay, levels of complications (McCue et al., 2003; Rothberg et al., 2005), and appropriate ward staffing levels (Thungjaroenkul et al., 2007 and Kane et al., 2007). When staff turnover is lowered (Jones, 2005 and 2008) and there is lower absenteeism (Silvestro and Silvestro, 2008) reduced indirect costs ensue.

Figure 1 summarises the research evidence illustrating the links between poor scheduling, poor patient care, nurse morale, reduced patient satisfaction, cost effectiveness and ultimately poor hospital performance. The unique challenge exerted by rescheduling and its impact has received less attention and remains unsupported by a clear understanding of its nature, consequences and how to respond managerially. 


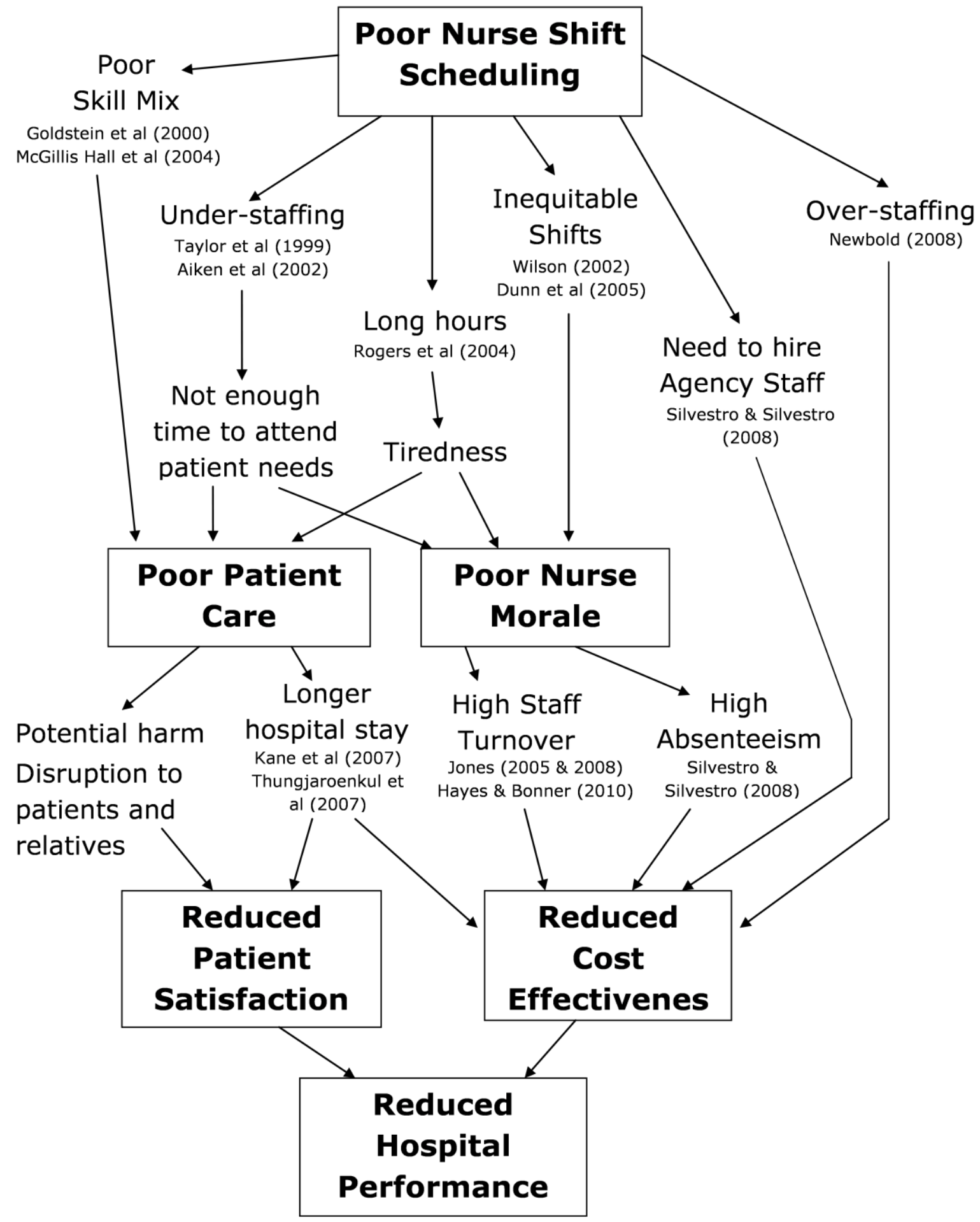

Figure 1. The consequences of poor staff scheduling 


\section{Evaluation of the Literature}

This review focuses specifically on rescheduling in the context of managing the nursing staff resource to maintain effective care delivery in hospital in-patient settings. The review was undertaken in order to synthesise existing understanding of the processes involved and outcomes of rescheduling on patient care, staff morale and cost, and to identify gaps for future research involving mathematical modelling tools.

\section{Method}

A search for articles containing the terms'nurse rerostering', 'staff rerostering', 'nurse rescheduling' and 'staff rescheduling' was carried out by the fourth author and reviewed by the first. The search used the CINAHL Plus and MEDLINE databases, multiple scientific databases via the SCIRUS search engine, 58 databases in the areas of health and social care accessed through the University of the West of England (UWE) library and finally across the Internet using Google Scholar.

\section{Selection criteria}

To be included in the review, articles had to relate to nurse scheduling or rescheduling, be published in peer-reviewed journals or conference abstracts, and available in English. To ensure quality, only articles from peer-reviewed journals and conferences were accepted. Articles published before 1980 were not included. Articles thus accepted were then searched for citations to find further articles. All articles were manually screened to determine whether they met the inclusion criteria.

\section{Scheduling Results and Analysis}

First of all, a similar search on scheduling was carried out using the phrases 'nurse rostering', 'staff rostering', 'nurse scheduling' and 'staff scheduling' in order to compare the number of rescheduling articles found with those on scheduling. An initial search produced 1348 articles with one of the four search phrases in the title, as shown in Table 1. By considering only those that discussed tools or models for nurse scheduling, this number was reduced to 299 articles. Further inspection and reading showed that just 61 of these article directly considered nurse scheduling (as opposed to mentioning it in articles about other topics). This radical reduction relied heavily on the authors' past experience in this field.

\begin{tabular}{|l|r|r|r|r|r|r|}
\hline Phrases in the Title & $\begin{array}{r}\text { Google } \\
\text { Scholar }\end{array}$ & $\begin{array}{r}\text { CINAHL } \\
\text { Plus }\end{array}$ & MEDLINE & $\begin{array}{r}\text { UWE } \\
\text { Library }\end{array}$ & SCIRUS & Total \\
\hline Nurse Scheduling & 328 & 9 & 1 & 46 & 239 & 623 \\
\hline Staff Scheduling & 200 & 18 & 30 & 52 & 177 & 477 \\
\hline Nurse Rostering & 11 & 6 & 7 & 28 & 161 & 213 \\
\hline Staff Rostering & 0 & 2 & 3 & 6 & 24 & 35 \\
\hline Total & 539 & 35 & 41 & 132 & 601 & 1348 \\
\hline
\end{tabular}

Table 1: Initial search phases and sources with the number of articles found. 
Scheduling models and systems designed for healthcare settings need to take account of the many constraints (Cheang et al., 2003) and local differences between wards (Malone et al., 1997), particular characteristics and needs of teams and individual staff members. To support this complex decision-making, a number of mathematical models have been developed, for example Berrada et al. (1996) and Jaumard et al. (1998). Most authors agree that the complexity of scheduling makes mathematical precision difficult which has led to the use of hybrid mathematical and computer-science approaches (Aickelin and Dowsland 2000, 2004, Aickelin and White 2004, and Brucker et al. 2005).

Fairness, the notion of equitable distribution and balance between individual requests and allocation of popular and unpopular shifts has been linked with staff satisfaction and morale(Wilson, 2002, Dunn et al, 2005). Aickelin and Dowsland (2000, 2004) accommodated fairness using a schedule constructed from predefined shift patterns. Each pattern was assigned a preference rating for each individual nurse, calculated as a weighted sum of a number of factors and agreed in consultation with the ward manager. Bard and Purnomo (2005a, 2005b) used mathematical models to identify acceptable levels of concession between managed and self-scheduling rostering approaches. Their model was developed with a limited number of 'candidate' shift schedules based on nurses' preferences or, if unavailable, a template based on the individual nurse's contract. The model quickly identified good quality schedules when tested on real and derived data with few preference violations (requests to change shifts) and a reduced dependency on temporary relief, bank or agency staff.

A review of research-based scheduling systems by Kellogg and Walczak (2007) found that less than $30 \%$ were implemented. Moreover little empirical evidence informed commercially available systems. They concluded that academic/commercial alliances would enhance nurse scheduling tools provided to hospitals. The range of mathematical and computational techniques used to model nurse scheduling is not the focus of this article and has been well reviewed elsewhere (Tein and Ramli 2010; Clark and Walker 2011). Rather the focus is the more complex problem of rescheduling. A key finding was that irrespective of the effectiveness of the research-based or commercially available rostering system, invariably management time and stress associated with rescheduling persisted, and these systems did little to reduce this burden (Bailyn et al. 2007).

\section{Rescheduling Results and Analysis}

The search for research on nurse rescheduling initially yielded 182 articles. On the basis of number of published outputs alone, rescheduling appears to have received much less attention compared to scheduling.

Figure 2 illustrates the rescheduling search process and results. On analysis of the abstracts of the 182articles identified, only 15 directly considered the problem of nurse rescheduling and these were included initially in this review. The excluded articles approached nurse rescheduling in relation to other activities (such as vaccination rates, the scheduling of nonnursing staff, the hospitalisation of children and post discharge patient care) rather than the rescheduling of the nursing workforce shifts. After removal of duplicates only six articles remained, hand searching yielded a further two articles. All the remaining articles had been published between 2003 and 2011. 


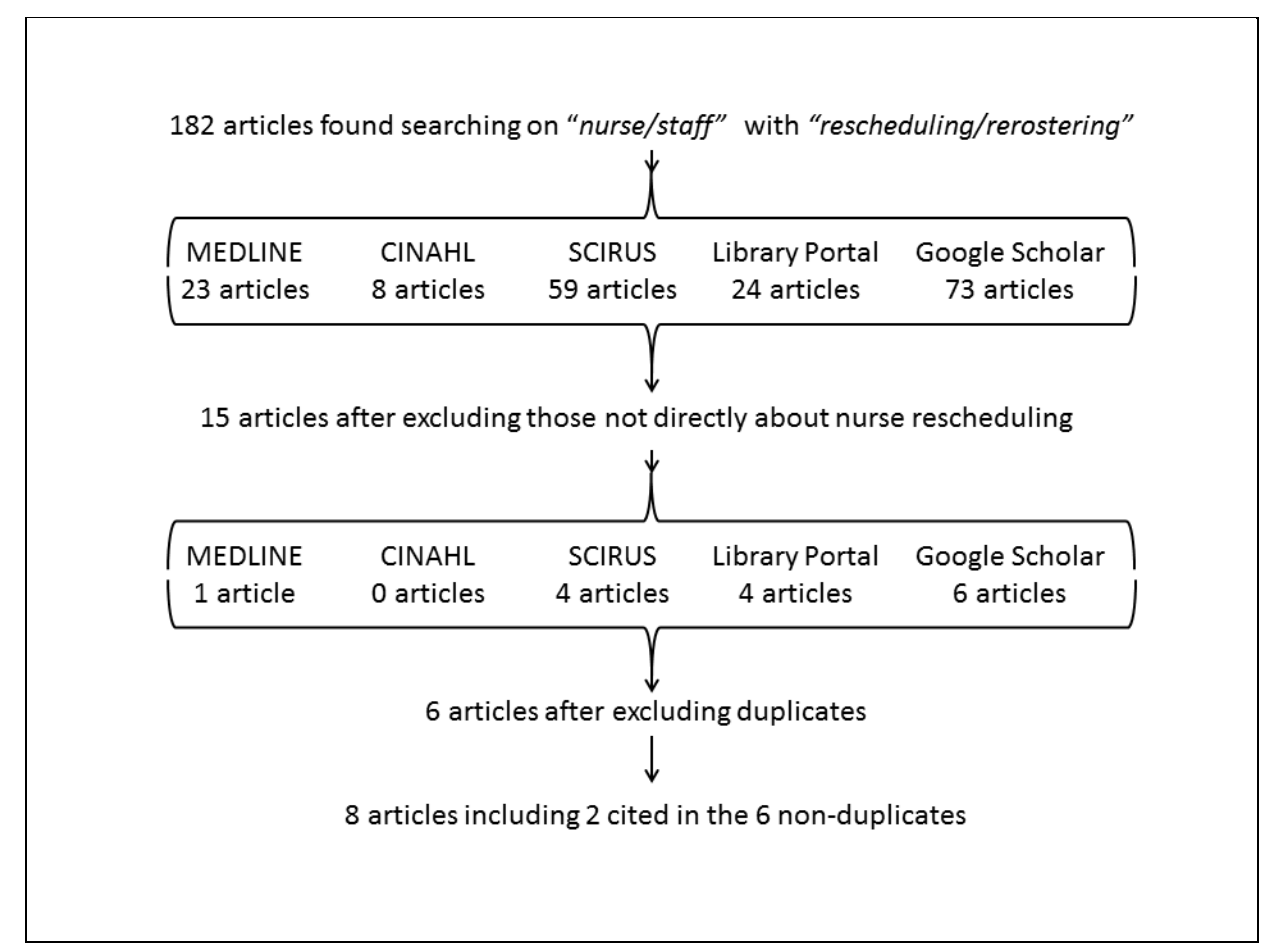

Figure 2: Rescheduling search process and results

The eight articles relating to rescheduling are described in Tables 2 and 3. All eight papers present the algorithms used to solve rescheduling challenges and are aimed at a technical mathematical computing audience. Only the work by Bard and Purnomo (2006) has been used in hospitals in both the USA and UK, although no subsequent published evaluation has been found. This highlights the problem that research on rerostering tends to be of a theoretical mathematical nature and has not yet produced any evidence that model-based tools can assist managers tasked with resolving staffing shortfalls. . 


\begin{tabular}{|l|l|l|}
\hline Authors & Title & Journal \\
\hline $\begin{array}{l}\text { Moz and Pato } \\
(2003)\end{array}$ & $\begin{array}{l}\text { An Integer Multicommodity Flow Model Applied to } \\
\text { the Rerostering of Nurse Rosters. }\end{array}$ & $\begin{array}{l}\text { Annals of Operations } \\
\text { Research, vol. 119, pp 285- } \\
\text { 301. }\end{array}$ \\
\hline $\begin{array}{l}\text { Moz and Pato } \\
\text { (2004) }\end{array}$ & $\begin{array}{l}\text { Solving the problem of rerostering nurse rosters with } \\
\text { hard constraints: new multicommodity flow models. }\end{array}$ & $\begin{array}{l}\text { Annals of Operations } \\
\text { Research, vol. 128, pp 179- } \\
197 .\end{array}$ \\
\hline $\begin{array}{l}\text { Bard and Purnomo } \\
\text { (2006) }\end{array}$ & $\begin{array}{l}\text { Incremental changes in the workforce to } \\
\text { accommodate changes in demand. }\end{array}$ & $\begin{array}{l}\text { Health Care Management } \\
\text { Science, vol. 9, issue 1, pp } \\
\text { 71-85. }\end{array}$ \\
\hline $\begin{array}{l}\text { Moz and Pato } \\
\text { (2007) }\end{array}$ & $\begin{array}{l}\text { A genetic algorithm approach to a nurse rescheduling } \\
\text { problem. }\end{array}$ & $\begin{array}{l}\text { Computers and Operations } \\
\text { Research, vol. 34, issue 3, pp } \\
\text { 667-691 }\end{array}$ \\
\hline $\begin{array}{l}\text { Pato and Moz } \\
\text { (2008) }\end{array}$ & $\begin{array}{l}\text { Solving a bi-objective nurse rescheduling problem by } \\
\text { using utopic Pareto genetic heuristics. }\end{array}$ & $\begin{array}{l}\text { Journal of Heuristics, vol. 14, } \\
\text { issue 4, pp 359-374 }\end{array}$ \\
\hline $\begin{array}{l}\text { Kitada, Morizawa } \\
\text { and Nagasawa } \\
\text { (2010) }\end{array}$ & $\begin{array}{l}\text { A heuristic method in nurse rerostering following a } \\
\text { sudden absence of nurses }\end{array}$ & $\begin{array}{l}\text { Proceedings of the 11 } \\
\text { Pacific Industrial } \\
\text { Engineering and } \\
\text { Management Systems } \\
\text { Conference, Manila. }\end{array}$ \\
\hline $\begin{array}{l}\text { Maenhout and } \\
\text { Vanhouke (2011) }\end{array}$ & $\begin{array}{l}\text { An evolutionary approach for the nurse rerostering } \\
\text { problem. }\end{array}$ & $\begin{array}{l}\text { Computers and Operations } \\
\text { Research, vol. 38, pp 1400- } \\
\text { 1411 }\end{array}$ \\
\hline (2011) & $\begin{array}{l}\text { Nurse rescheduling with shift preferences and } \\
\text { minimal disruption }\end{array}$ & $\begin{array}{l}\text { Journal of Applied } \\
\text { Operational Research, vol. 3, } \\
\text { issue 3, pp 148-162 }\end{array}$ \\
\hline
\end{tabular}

Table 2: The eight articles relating to rescheduling. 


\begin{tabular}{|c|c|c|c|c|c|c|}
\hline Authors & Country & Technique & $\begin{array}{l}\text { Technique } \\
\text { Tested Using }\end{array}$ & $\begin{array}{l}\text { Put into } \\
\text { Practice? }\end{array}$ & $\begin{array}{l}\text { Usability } \\
\text { consider } \\
\text { ed? }\end{array}$ & $\begin{array}{l}\text { Type of } \\
\text { Unit }\end{array}$ \\
\hline $\begin{array}{l}\text { Moz and Pato } \\
(2003)\end{array}$ & Portugal & $\begin{array}{l}\text { Mathematical } \\
\text { Optimisation }\end{array}$ & $\begin{array}{l}\text { Real data from a } \\
\text { Lisbon hospital }\end{array}$ & No & No & $\mathrm{N} / \mathrm{A}$ \\
\hline $\begin{array}{l}\text { Moz and Pato } \\
(2004)\end{array}$ & Portugal & $\begin{array}{l}\text { Mathematical } \\
\text { Optimisation }\end{array}$ & $\begin{array}{l}\text { Real data from a } \\
\text { Lisbon hospital }\end{array}$ & No & No & $\mathrm{N} / \mathrm{A}$ \\
\hline $\begin{array}{l}\text { Bard and } \\
\text { Purnomo (2006) }\end{array}$ & USA & $\begin{array}{l}\text { Mathematical } \\
\text { Optimisation }\end{array}$ & Synthetic data & Yes & Yes & $\begin{array}{l}\text { 400-bed } \\
\text { Intensive } \\
\text { Care Unit } \\
\text { with } 80 \\
\text { nurses }\end{array}$ \\
\hline $\begin{array}{l}\text { Moz and Pato } \\
(2007)\end{array}$ & Portugal & $\begin{array}{l}\text { Intelligent } \\
\text { Computerised } \\
\text { Search }\end{array}$ & $\begin{array}{l}\text { Real data from a } \\
\text { Lisbon hospital }\end{array}$ & No & No & $\mathrm{N} / \mathrm{A}$ \\
\hline $\begin{array}{l}\text { Pato and Moz } \\
(2008)\end{array}$ & Portugal & $\begin{array}{l}\text { Intelligent } \\
\text { Computerised } \\
\text { Search }\end{array}$ & $\begin{array}{l}\text { Real data from a } \\
\text { Lisbon hospital }\end{array}$ & No & No & $\mathrm{N} / \mathrm{A}$ \\
\hline $\begin{array}{l}\text { Kitada, Morizawa } \\
\text { and Nagasawa } \\
(2010)\end{array}$ & Japan & $\begin{array}{l}\text { Intelligent } \\
\text { Computerised } \\
\text { Search }\end{array}$ & $\begin{array}{l}\text { Real data from a } \\
\text { Japanese } \\
\text { hospital }\end{array}$ & No & No & N/A \\
\hline $\begin{array}{l}\text { Maenhout and } \\
\text { Vanhouke (2011) }\end{array}$ & Belgium & $\begin{array}{l}\text { Intelligent } \\
\text { Computerised } \\
\text { Search }\end{array}$ & Synthetic data & No & No & $\mathrm{N} / \mathrm{A}$ \\
\hline $\begin{array}{l}\text { Clark and Walker } \\
(2011)\end{array}$ & UK & $\begin{array}{l}\text { Mathematical } \\
\text { Optimisation }\end{array}$ & Synthetic data & No & No & $\mathrm{N} / \mathrm{A}$ \\
\hline
\end{tabular}

Table 3: Rerostering article information

The key principle underscoring rescheduling decision-making is to minimise any disruption caused to the previously published schedule whilst maintaining quality nursing cover. This is the imperative considered by all eight articles in Tables 1 and 2 .

Moz and Pato $(2003,2004,2007)$ describe attempts to minimise change to the original schedule as little as possible. Their three papers are mathematics or computer-science focused and provide few details about the hospital in Lisbon, Portugal, that motivated their research. Their eventual aim was to supply nurse managers with rapid high quality rescheduling, but the papers do not provide any information on the practical implementation of the research.

Bard and Purnomo (2006) addressed a different rescheduling problem that they term 'reactive scheduling' whereby the 24-hour shift cycle is reviewed at a specific time. They began with a 6-week base schedule and then reviewed each shift a couple of hours prior to its start, and made amendments where necessary. Their method could reschedule up to 200 nurses and gave the nurse manager a set of options that included rescheduling and employing part-time or external staff. This was the only one of the eight articles described in Table 2 that reported outcomes of implementation in a hospital setting. Unfortunately no follow-up report has been found describing the impact of the system on patient care outcomes or staff morale.

Kitada et al. (2010) and Maenhout \& Vanhouke (2011) developed and numerically tested intelligent computer search methods. The emphasis of both papers was on the algorithmic nature of the heuristic. Kitada et al. (2010) did not consider any operational aspects of how effective it might be in practice. This limitation is also the case for the Maenhout \& 
Vanhouke (2011) who emphasize their method's high-quality numerical results with benchmark datasets from the research literature rather than testing it in a hospital.

Lastly Clark and Walker (2011) used mathematical programming models to produce rosters. They developed a disruption matrix that could be used to maintain some continuity with the original schedule creating less disruption to nurse's preferences and planned individual rosters. Their emphasis was on models that can be solved with industry-standard commercial optimisation software that is fast enough for operational use; however, their models have yet to be validated in practice.

\section{Consultation Exercise}

Our search methods identified no research literature that provided insight into the perspective of managers involved in staff rescheduling. To overcome this omission we approached four different NHS trusts (a medium sized secondary and community care provider, a large inner city Teaching Hospital and a mental health organisation providing a range of in and out reach services to rural and urban populations) to better understand the managerial day-to-day burden presented by rescheduling at a ward, unit and organisational level. This exercise could best be described as fact finding with potential end users (nurse managers) and did not adopt formal research methods. It therefore fell outside the requirements for NHS research ethics and governance (National Patient Safety Agency 2009,) however every attempt to follow principles of good research practice were made. We spoke with executive nurses $(n=2)$, managers involved in resolving staff shortages at unit or site level $(n=2)$ and ward managers $(n=3)$ across the four organisations. Our discussions focussed on what they saw as the daily challenges associated with rerostering and their solutions and these were captured in notes. No attempt was made to obtain a representative sample as this exercise was intended to define the nature and scope of the problem prior to designing a more substantive research project and ultimately prototype. The following summarises the key issues raised by the seven managers who participated in those discussions:

1. Nurse scheduling was a recognisably strategic concern due to a perceived clear relationship between appropriate levels and skill-mix of staff, quality of patient care, and cost implications of poor rescheduling decision-making.

2. Unfilled rostered shifts were seen as a risk with potential for negative consequences if emergency situations arose, contributing to the number of adverse events, failure to retrieve deteriorating patients, infection rates and staff morale.

3. Time spent preparing monthly scheduling was already a time consuming management role (e.g. a day a month), yet rescheduling activity was a daily organisational activity and could take up a significant amount of a ward and hospital manager's time.

4. Rerostering required speedy and sometimes immediate decision-making

5. If rescheduling was required, then a ladder of decision-making and accountability ensued as follows:

(a) Evaluate whether the ward/unit could manage with the shift unfilled.

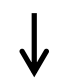

(b) Fill vacant shifts with staff familiar with the environment:

- Invite existing staff to work additional hours (paid/time in lieu)

- Approach off duty staff to change shifts,

- Ask specific staff known to accommodate late requests to work. 


\section{$\downarrow$}

(c) Ask the next tier of management to identify relief staff from elsewhere in the organisation.

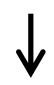

(d) Approach a staff bank at additional cost, recognising that like-for-like replacements are unlikely to be available.

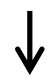

(e) As a last resort, bring in agency staff, an expensive option that most managers try to avoid. However, Snow (2012) suggests that use of agency staff is increasing as there is less 'slack' in the system to accommodate options A to D.

The managers perceived that staff felt reasonable rescheduling was fair and inevitable. Urgent short-notice off-duty requests were often the most difficult to meet, and increasingly requests for preferred shifts were challenging. The difficulty of finding staff resources within the preferential nature of the rescheduling decision process was very different to that for oneoff scheduling.

These insights, in common with the nurse rostering and scheduling literature, suggest that rerostering impacts on quality, costs and morale. In addition the burden of rescheduling decision-making was characterised as both time consuming and demanding urgent attention. Ward managers who participated described typically spending approximately one day a month producing the schedule, with some senior managers then spending $10 \%$ to $20 \%$ of most working days rescheduling to cope with absenteeism and changes in the staff required.

The decision-making described in 5(a)-(e) above reveals the uniqueness of rescheduling when compared to scheduling. It also illustrates the potential value for managers of effective methodological support that could accommodate the complexity required for staff rescheduling.

Our consultation exercise also revealed that automation of scheduling processes was variable across trusts. At one trust scheduling software was trialled but the staff did not perceive any advantage in using it and so the paper based system was retained. A second organisation had introduced nurse scheduling software, but due to the lack of training and support, its adoption has been poor, and most areas were still using a paper-based system. A third trust had trialled a system but could not find the financial resource to invest in a contract. Only one trust had introduced nurse scheduling software across all areas. These anecdotal accounts mirror the findings about uptake of automation described in the published literature (Kellogg and Walczak, 2007, Bailyn et al.2007).More pertinently to this paper, while some systems offer mathematical optimisation support for staff scheduling (Brucker et al., (2005), no automated systems were identified that specifically support the unique nature, and complexity of rescheduling decision-making processes for nursing staff.

\section{Key Issues}

The most important issues to emerge from the analysis are as follows:

1. Nurse scheduling carries risk and is a strategic issue with implications for the quality of care, staff morale and retention, and the cost of care. 
2. Short-term rescheduling is a frequent almost-daily activity.

3. To be effective, rescheduling needs to accommodate additional factors beyond those considered in the original schedule, namely to keep to a minimum the disruption from the shift patterns already rostered for individual staff. In rescheduling this often becomes a ward, unit and organisation imperative not merely confined to one staff team in isolation unlike initial scheduling.

4. Ineffective rescheduling can impact on the quality of care, damage staff morale, and increase the cost of care, compared to the original staff schedule.

5. There is currently little mathematical or computational support for rescheduling. In practice, it is an informal task although skilled activity that can occupy a significant proportion of ward and senior managers' time.

6. Existing computer-aided systems for scheduling do not explicitly consider rescheduling.

The analysis has shown that, while staff scheduling is a strategic concern for managers, rescheduling is an even bigger issue due to the greater number of factors involved and its operational urgency. No methodological automated support is currently available. The research on rescheduling is exclusively mathematical or algorithmic, but none of the proposed methods has been operationally evaluated in practice. There is no research literature on the implementation, validation or managerial aspects of rescheduling methodologies; hence our consultation exercise with managers was a rich and valuable source of real world information.

\section{Discussion and Implications for Nursing Management}

This analysis identified serious implications for nursing managers. We have found that rescheduling is a strategic issue that impacts on the quality of care, its cost, staff morale and consumes significant managerial time. The lack of specific methodological support that takes into account the complexity of rescheduling increases the likelihood of harm to patients and stress for nursing staff and managers.

These considerations motivate the development of mathematical support to assist managers in rescheduling staff. Clark and Walker (2011) proposed a model for purpose, but it requires testing in hospital settings in order to evaluate its potential. The results of this review of the literature and consultation exercise suggest research is needed to answer a number of questions in order to inform an operable system. These include:

- How can progress from paper-based or informal rescheduling to using mathematical support be best conducted in order to improve and speed up day-to-day rescheduling decision-making?

- How automated should such support be? - as any new system should not add an unnecessary additional burden on users. Specifically, should any support be added to provide additional intelligence to already populated spreadsheets? - given that managers are familiar with this technology and way of presenting information to inform decision-making. Or should it involve the use of specialist software that may require user support but offer greater specificity for problem-solving?

- What are the human issues including risk management and error minimisation? 
- What end-user support and training would managers require?

- How could a feasibility study be undertaken to identify possible (dis)benefits of mathematical support for rescheduling to improve manager and organisational productivity?

\section{Conclusions}

The review of the literature showed that very little research has been conducted on nurse shift rescheduling. The limited research so far has been based on mathematical-modelling and computer-search approaches that have yet to be tested in operational practice. The scoping exercise with nursing managers clearly indicated that it is a regular and time consuming management activity which is more complex and challenging than one-off scheduling. Poor rescheduling decision-making is perceived to have serious implications for patient safety, cost minimisation and staff morale.

There is thus potential for a tool to support nursing managers to manage service disruption and minimise its impact. Mathematical modelling could fill this gap by capturing some of the quantitative complexity and providing optimised decision advice for managers to use in conjunction with their own experience and judgement. The effectiveness of such a tool should be demonstrated using staffing data, before and after its introduction, to calculate metrics on ward skill mix, understaffing, overstaffing, hours worked and the frequency of hiring bank and agency staff. Before and after staff surveys should be used to gauge the fairness of the rescheduling tool.

In summary, rescheduling, the activity that occurs when individual rostered staff unexpectedly become unavailable, is a frequent and difficult challenge in healthcare organisations despite good planning. A mathematical decision-support tool would help managers make considered, operationally robust and speedier rescheduling decisions.

\section{References}

Aickelin U. and Dowsland K.A. (2000) Exploiting problem structure in a genetic algorithm approach to a nurse rostering problem. Journal of Scheduling 3 (3), 139-153.

Aickelin U. and Dowsland K.A. (2004) An indirect Genetic Algorithm for a nurse-scheduling problem. Computers and Operations Research 31, 761-778.

Aickelin U. and White P. (2004) Building Better Nurse Scheduling Algorithms. Annals of Operations Research 128, 159-177.

Aiken L.H., Clarke S.P., Sloane D.M., Sochalski J. and Silber J.H. (2002) Hospital Nurse Staffing and Patient Mortality, Nurse Burnout and Job Dissatisfaction. Journal of the American Medical Association 288 (16), 1987-1993.

Aiken L.H., Sermeus W., Van den Heede K., Sloane D.M., Busse R., McKee M., Bruyneel L., Rafferty A.M., Griffiths P., Moreno-Casbas M.T., Tishelman C., Scott A., Brzostek T., Kinnunen J., Schwendimann R., Heinen M., Zikos D., Sjetne I.S., Smith H.L. and Kutney- 
Lee A. (2012) Patient safety, satisfaction, and quality of hospital care: cross sectional surveys of nurses and patients in 12 countries in Europe and the United States. British Medical Journal 344: e1717.doi: 10.1136/bmj.e1717.

Bailyn L, Collins R and Song Y (2007) Self-scheduling for hospital nurses: an attempt and its difficulties, Journal of Nursing Management 15(1): 72-77.

Bard J.F. and Purnomo H. W. (2005a) Preference scheduling for nurses using column generation, European Journal of Operational Research, 510-534.

Bard J.F. and Purnomo H.W. (2005b) Short-Term Nurse Scheduling in Response to Daily Fluctuations in Supply and Demand. Health Care Management Science 8, 315-324.

Bard J.F. and Purnomo H.W. (2005c) Hospital-wide reactive scheduling of nurses with preference consideration. IIE Transactions 37, 589-608.

Bard J. F. and Purnomo H.W. (2005d) A column generation-based approach to solve the preference scheduling problem for nurses with downgrading, Socio-Economic Planning Sciences, pp. 193-213.

Bard J.F. and Purnomo H.W. (2006) Incremental changes in the workforce to accommodate changes in demand. Health Care Management Science. 9 (1), 71-85.

Bard J. F. and Purnomo H. W. (2007) Cyclic preference scheduling of nurses using a Lagrangian-based heuristic. , Journal of Scheduling, 5-23.

Berrada I., Ferland J.A. and Michelon P. (1996) A Multi-objective Approach to Nurse Scheduling with both Hard and Soft Constraints. Socio-Economic Planning Sciences 30 (3) 183-193.

Brucker P., Qu R., Burke E. and Post G. (2005) A decomposition, construction and postprocessing approach for nurse rostering. Proceedings of the 2nd Multidisciplinary International Conference on Scheduling: Theory and Applications (MISTA), Volume 1, New York, USA (18-21 July 2005), 397-406.

Butler M., Collins R., Drennan J., Halligan P., O’Mathúna D.P., Schultz T.J., Sheridan A. and Vilis E. (2011) Hospital nurse staffing models and patient and staff-related outcomes (Review).Cochrane Database of Systematic Reviews, 7, John Wiley and Sons, Ltd.DOI: 10.1002/14651858.CD007019.pub2

Cheang B., Li H., Lim A. and Rodrigues B. (2003) Nurse rostering problems-a bibliographic survey. European Journal of Operational Research 151, 447-460.

Clark A.R. and Walker H. (2011) Nurse rescheduling with shift preferences and minimal disruption. Journal of Applied Operational Research 3 (3), 148-162.

Dunn S., Wilson B. and Esterman A. (2005) Perceptions of working as a nurse in an acute care setting. Journal of Nursing Management 13, 22-31. 
Ernst, A T, Jiang H., Krishnamoorthy M. and Sier D. (2004) Staff scheduling and rostering: A review of applications, methods and models. European Journal of Operational Research, 153 (1), 3-27.

Goldstein M., Braitman L.E. and Levine G.M. (2000) The Medical and Financial Costs Associated with Termination of a Nutrition Support Nurse. Journal of Parenteral and Enteral Nutrition 24, 323-327.

Hayes B. and Bonner A. (2010). Job satisfaction, stress and burnout associated with haemodialysis nursing: a review of literature. Journal of Renal Care 36 (4), 174-179.

Hegney D., Plank A. and Parker V. (2006) Extrinsic and Intrinsic Work Values: Their Impact on Job Satisfaction in Nursing. Journal of Nursing Management 14 (4), 271-281.

Jaumard B., Semet F. and Vovor T. (1998) A generalized linear programming model for nurse scheduling. European Journal of Operational Research 107 (1), 1-18.

Jones, C.B. (2005) The Costs of Nurse Turnover, Part 2: Application of the Nursing Turnover Cost Calculation Methodology. Journal of Nursing Administration 35 (1), 41-49.

Jones, C.B. (2008) Revisiting Nurse Turnover Costs: Adjusting for Inflation. Journal of Nursing Administration 38 (1), 11-18.

Kane R.L., Shamliyan T.A., Mueller C., Duval S. and Wilt T.J. (2007) The Association of Registered Nurse Staffing Levels and Patient Outcomes: Systematic Review and MetaAnalysis. Medical Care 45 (12), 1195-1204.

Kellogg D.L. and Walczak S. (2007) Nurse Scheduling: From Academia to Implementation or Not? Interfaces 37 (4), 355-369.

Kitada, Morizawa and Nagasawa (2010), A Heuristic Method in Nurse Rerostering Following a Sudden Absence of Nurses, Proceedings of the 11th Asia Pacific Industrial Engineering and Management Systems Conference, Manila.

Kostreva M., McNelis E. and Clemens E. (2002) Using a circadian rhythms model to evaluate shift schedules, Ergonomics, 45 (11), 739-763.

Maenhout B. and Vanhoucke M. (2011) An evolutionary approach for the nurse rerostering problem. Computers and Operations Research 38, 1400-1411.

Malone N., Loader S. and Poulter J. (1997) Evaluating the benefits realized from a nurse management information system. Journal of Nursing Management 5, 5-9.

McCue M., Mark B.A. and Harless D.W. (2003) Nurse Staffing, Quality and Financial Performance. Journal of Health Care Finance 29 (4), 54-76.

McGillis Hall L., Doran D. and Pink G.H. (2004) Nurse Staffing Models, Nursing Hours and Patient Safety Outcomes. Journal of Nursing Administration 34 (1), 41-45. 
Moz M. and Pato M.V. (2003) An Integer Multicommodity Flow Model Applied to the Rerostering of Nurse Schedules. Annals of Operations Research 119, 285-301.

Moz M. and Pato M.V. (2004) Solving the Problem of Rerostering Nurse Schedules with Hard Constraints: New Multicommodity Flow Models. Annals of Operations Research 128, 179-197.

Moz M. and Pato M.V. (2007) A genetic algorithm approach to a nurse rerostering problem. Computers and Operations Research 34 (3), 667-691.

National Patient Safety Agency (2009) Defining Research London: National Research Ethics Service download from http://www.nres.nhs.uk/applications/is-your-project-research/ [accessed 26.03.13]

Needleman J., Buerhaus P., Mattke S., Stewart M., and Zelevinsky K. (2002) Nurse-Staffing Levels and the Quality of Care in Hospitals. New England Journal of Medicine 346, 17151722.

Newbold D. (2008) The production economics of nursing: A discussion paper. International Journal of Nursing Studies 45, 120-128.

Pato M.V. and Moz M. (2008) Solving a bi-objective nurse rerostering problem by using a utopic Pareto genetic heuristic. Journal of Heuristics 14, 359-374.

Pryce, J., Albertsen, K. and Nielsen, K. (2006). Evaluation of an open-rota system in a Danish psychiatric hospital: a mechanism for improving job satisfaction and work-life balance, Journal of Nursing Management 14: 282-288.

Rafferty A.M., Clarke S.P., Coles J., Ball J, James P., McKee M., and Aiken L.H. (2007) Outcomes of variation in hospital nurse staffing in English hospitals: Cross-sectional analysis of survey data and discharge records. International Journal of Nursing Studies 44 (2), 175182.

Rogers A.E., Hwang W.T., Scott L.D., Aiken L.H. and Dinges D.F. (2004) The Working Hours Of Hospital Staff Nurses And Patient Safety. Health Affairs 23 (4), 202-212.

Rothberg M.B., Abraham I., Lindenauer P.K. and Rose D.N. (2005) Improving Nurse-toPatient Staffing Ratios as a Cost-Effective Safety Intervention. Medical Care 43 (8), 785-791.

Silvestro R. and Silvestro C. (2008) Towards a model of Strategic Roster Planning and Control: an empirical study of nurse rostering practices in the UK National Health Service. Health Services Management Research 21: 93-105.

Snow T, (2012) Concern over the knock-on effects of growing gaps in nursing roster Nursing Standard 26 (42), 12-13.

Taylor S., White B. and Muncer S. (1999) Nurses' cognitive structural models of work-based stress. Journal of Advanced Nursing 29 (4), 974-983. 
Thungjaroenkul P., Cummings G.G. and Embleton A. (2007) The Impact of Nurse Staffing on Hospital Costs and Patient Length of Stay: A Systematic Review. Nursing Economic\$ 25 (5), 255-265.

Tein L.H. and Ramli R. (2010) Recent Advancements of Nurse Scheduling Models and A Potential Path. Proceedings of the 6th IMT-GT Conference on Mathematics, Statistics and its Applications (ICMSA2010), 395-409.

Wilson J.L. (2002) The impact of shift patterns on healthcare professionals. Journal of Nursing Management 10, 211-219. 